\title{
Effects of HIP Treatment on the Microstructure of Cr50-Si50 Target
}

\author{
Chung-Hung Tam ${ }^{1, *}$, Shih-Chin Lee ${ }^{1}$, Shih-Hsien Chang ${ }^{1}$, Tzu-Piao Tang ${ }^{2}$, \\ Hsin-Hung $\mathrm{Ho}^{3}$ and Hui-Yun Bor ${ }^{3}$ \\ ${ }^{1}$ Department of Materials Science and Engineering, National Cheng Kung University, Tainan, Taiwan, 701, R. O. China \\ ${ }^{2}$ Department of Materials and Mineral Resources Engineering, National Taipei University \\ of Technology, Taipei, Taiwan, 106, R. O. China \\ ${ }^{3}$ Materials and Electro-Optics Research Division of Chung-Shan Institute of Science \\ and Technology, Lung-tan, Taiwan, 325, R. O. China
}

Hot Isostatic Pressing (HIP) is a process that uniquely combines higher pressure and temperature to produce materials and parts with substantially better properties than those fabricated by other methods. Commercial as-hp (hot pressing) treated Cr50-Si50 targets are used throughout this study. The aim of this paper is to discuss the methods and to find a suitable HIP treatment for the as-hp treated Cr50-Si50 target. Otherwise, we also to find the effects of microstructure on the mechanical properties of HIP treated Cr50-Si50 target. To evaluate the effects on microstructure and properties of the Cr50-Si50 target by HIP process, SEM, TEM and porosity, density inspections were performed. The experiment results show that HIP treatment at $1373 \mathrm{~K}$ under the pressure of $175 \mathrm{MPa}$ and 4 hours for Cr50-Si50 target is the optimum condition. In this study, HIP treatment reduced the porosity of the target about 60\%. [doi:10.2320/matertrans.MER2007166]

(Received July 13, 2007; Accepted December 4, 2007; Published January 25, 2008)

Keywords: hot isostatic pressing, hot pressing, chromium50-silicon50 target, porosity, density

\section{Introduction}

Hot pressing (HP) is putting the powder in a die and applying force with vertical (or horizontal) pressure heads. Many silicides of refractory metal offer desirable properties for physical and chemical such as high melting point, good oxidation resistance, high strength, and excellent creep resistance at elevated temperatures. ${ }^{1-3)}$ And Chromium Silicides are mainly applied in thin film resistor and heater. Since $\mathrm{Cr}$ and $\mathrm{Si}$ are active and brittle, when the target is produced by casting, both elements would be oxidized and the target may have crack during casting. The poor quality such as purity and density of the targets are unacceptable for thin film deposition. Thus we need to make the $\mathrm{Cr}$-Si targets by other advanced methods like hot isostatic pressing. The products made by hot pressing may still be porous, and the size is limited by the die. For denser and larger targets, we can apply hot isostatic pressing to achieve our aim. ${ }^{4-7)}$

Hot Isostatic Pressing (HIP) is a process that uniquely combines higher pressure and temperature to produce materials and parts with substantially better properties than those by other methods. It is a material pressing technique that high isostatic pressure is applied to a powder part or compact at elevated temperature to produce particle bonding. ${ }^{8-10)}$ Functions of HIP processes include defect healing of castings, removal of internal porosity, diffusion bonding of dissimilar materials, improvement in property scatter and mechanical properties. ${ }^{11-14)}$

In this study, we were afraid that the $\mathrm{Cr}$-Si target would react with nitrogen or oxygen during HIP, thus we used argon as the atmosphere. We took three different temperatures and two kinds of soaking time for HIP. And we took some tests to confirm the effect of HIP treatment.

${ }^{*}$ Corresponding author, E-mail: asbeltam@so-net.net.tw

\section{Experimental}

Both of chromium and silicon are rapidly oxidized, and powder metallurgy is usually used to make targets out of such materials, especially in hot pressing. To achieve better quality targets, we should use some advanced methods such as hot isostatic pressing. HIP involves the application of high pressures and temperatures through the medium of a pressurized gas such as argon or nitrogen, to remove internal pores and voids, thus increasing density and upgrading properties. HIP consolidates powders of metals, ceramics, carbides into fully dense, complex parts with net or near net shapes. ${ }^{15-17)}$

The aim of this paper is to discuss the methods and to find a suitable temperature of HIP treatment for $\mathrm{Cr} 50-\mathrm{Si} 50$ target. Otherwise, we also to find the effects of microstructure on the mechanical properties of HIP treated Cr50-Si50 target. In the experiment, we draw air away from the pressure vessel to make a low vacuum environment, and we applied argon as the HIP atmosphere. The pressure was maintained at $175 \mathrm{MPa}$, the soaking time were 2 and 4 hours, three different temperatures were 1323, 1373 and $1423 \mathrm{~K}$. Commercial as-hp treated Cr50-Si50 (Cr-50 mass $\% \mathrm{Si}$ ) targets were used throughout this study, they were made by a $1273 \mathrm{~K}, 50 \mathrm{MPa}$ die. To evaluate the effects of microstructure and properties of the Cr50-Si50 target by HIP process, SEM, TEM and porosity, density inspections were performed.

SEM images are formed through secondary and backscattered electrons as secondary electron image (SEI) and back-scattered electron image (BEI). The $\mathrm{Cr}$ and $\mathrm{Si}$ contents of the phases were detected by microanalysis via EDS, and the results would compare with SEI and BEI. We measure the porosity of the targets by the method of ASTM C373-88. ${ }^{18)}$ Before we filled argon as the HIP atmosphere, there was still a little air about nitrogen and oxygen in the chamber because 


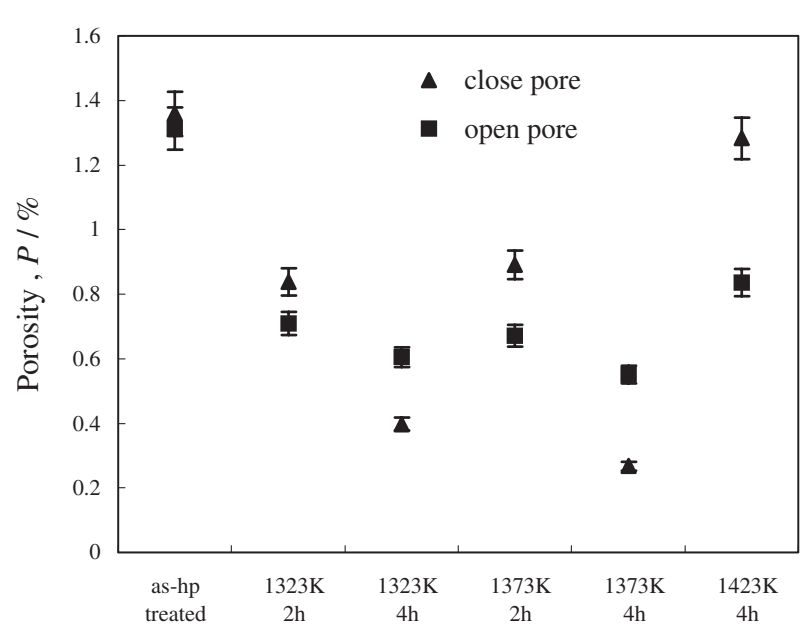

Fig. 1 Comparison of the porosities of as-hp treated and after different HIP treatment for Cr50-Si50 target.

of low vacuum. The residual air might store in the porosity or form some compounds as the impurities inside the $\mathrm{Cr}-\mathrm{Si}$ targets. They would be measured by the concentrations of nitrogen and oxygen analyzer with vaporizing the small chips from them.

\section{Results and Discussion}

\subsection{Porosity test}

The porosity test followed the ASTM C373-88 standard. During HIP plastic flow, power law creep and grain boundary sliding in the particles and bulk diffusion in the particle contacts may contribute to the densification. ${ }^{5)}$ Figure 1 represents the porosity of $\mathrm{Cr} 50-\mathrm{Si} 50$ target of as-hp treated and after HIP treatment at different temperatures. It shows the porosity of open pores was significantly reduced at 1323 and $1373 \mathrm{~K}$ HIP treatment, but the close pores' one reduced not so definite both of 1323 and $1373 \mathrm{~K}, 2 \mathrm{~h}$ HIP treatment. This is because the open pores filled and covered with the diffusive materials by HIP. With the soaking time became longer, the materials diffused into the close pores more and more. The close porosity of $2 \mathrm{~h}$ HIP would be just slightly down, because the close pores were still not filled enough with the materials. The porosity of open pore for Cr50-Si50 target was reduced down to $40 \%$ from the as-hp one after HIP treatment at $1373 \mathrm{~K}, 4 \mathrm{~h}$. When the temperature of HIP was increased to $1423 \mathrm{~K}$, the porosity rapidly increased. This is because the Cr-Si target was overheated in the high temperature and pressure environment, and the surface materials melted locally. The gas can get into the target easier at $1423 \mathrm{~K}$ than the temperature at 1323 or $1373 \mathrm{~K}$. After HIP, the target was cooling down, and the gas would form more pores, either open or close. Figure 2 shows the pore size distribution detected by mercury intrusion porosimetry (SCIENTEK CORPORATION, STK019348) of as-hp treated and after HIP treatment at $1373 \mathrm{~K}$ with 4 hours. For the ashp Cr-Si target, the main pore size was distributed at $10 \mathrm{~nm}$, and it would be significantly eliminated after HIP treatment. The porosity is smoothed away and reduced after HIP treatment.

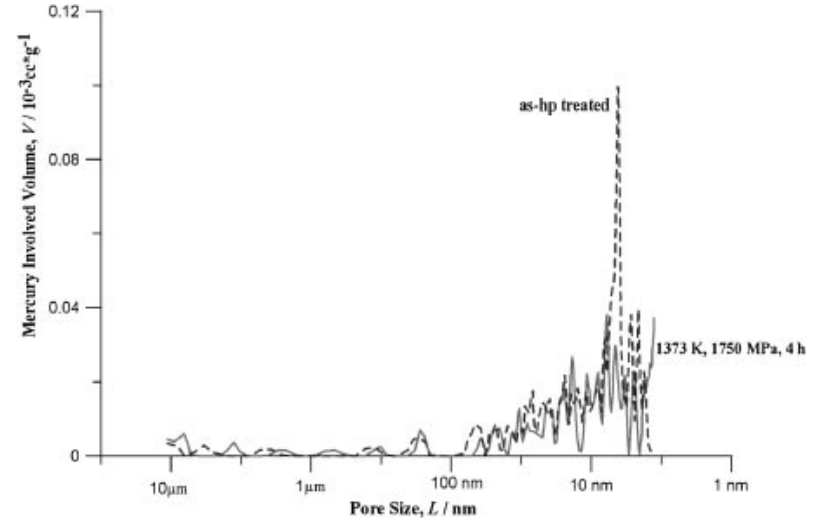

Fig. 2 Comparison of the pore size of as-hp treated and after $1373 \mathrm{~K}$, $175 \mathrm{MPa}, 4 \mathrm{~h}$ HIP treatment for Cr50-Si50 target.

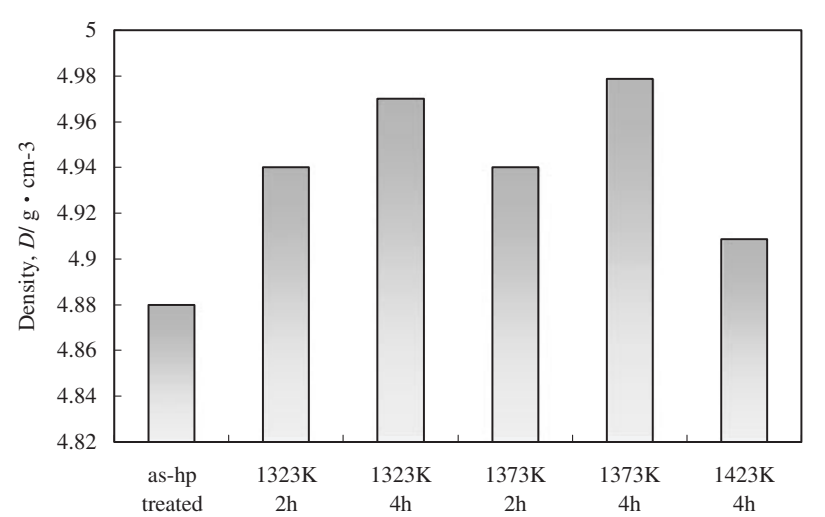

Fig. 3 Comparison of the density of as-hp treated and after different HIP treatment for Cr50-Si50 target.

\subsection{Density test}

Figure 3 presents the Cr50-Si50 target density of as-hp treated and HIP treatment at different temperatures. It shows the density increases after HIP. At the same HIP temperature, it became more efficient in enhancing density with the longer soaking time we dealt. At the temperature of $1373 \mathrm{~K}$ and the soaking time of 4 hours, we can get the optimal density about $4.98 \mathrm{~g} / \mathrm{cm}^{3}$. In general the density increases with the HIP temperature climbing up, but it became lower for the temperature raised from $1373 \mathrm{~K}$ to $1423 \mathrm{~K}$ because of the increasing amount of open and closed pores. The results are calculated by the ASTM C373-88 standard after the porosity testing. Thus the density is related to the porosity showed in Fig. 1.

\subsection{Concentrations of nitrogen and oxygen}

Figure 4 shows the nitrogen and oxygen concentrations of as-hp treated and after HIP treatment at different temperatures for $\mathrm{Cr} 50-\mathrm{Si} 50$ target. The results show that the concentrations of oxygen impurities would not change so much after HIP treatment. The nitrogen concentrations were decreased slightly on the Cr50-Si50 target after different temperature for HIP treatment. It seems that oxygen is more active than nitrogen. There was still residual air inside the vessel before heating and filling argon as the HIP atmosphere. It was hard for the low vacuum system to eliminate the nitrogen and oxygen completely during HIP process. 


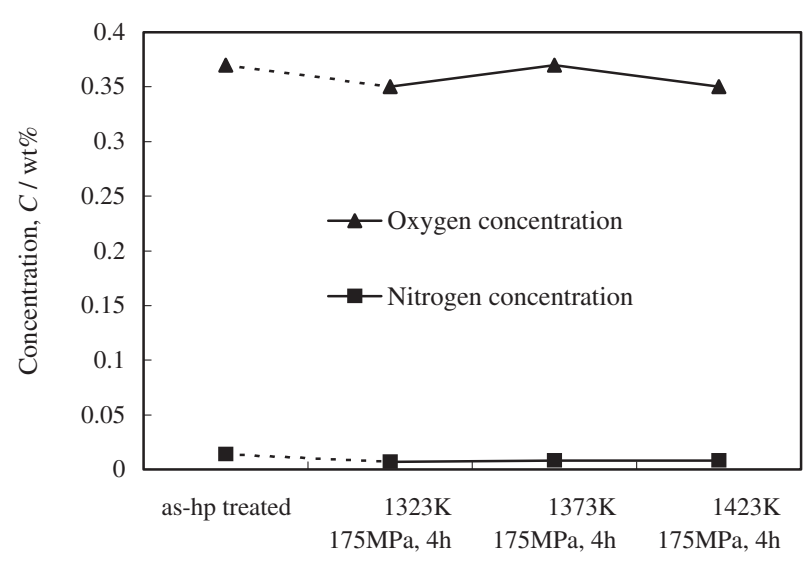

Fig. 4 Comparison of the nitrogen and oxygen concentration of as-hp treated and after HIP treatment at different temperatures for Cr50-Si50 target.

(a)

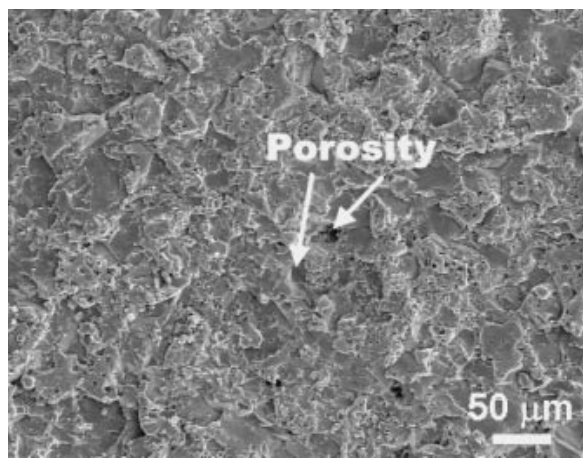

(c)

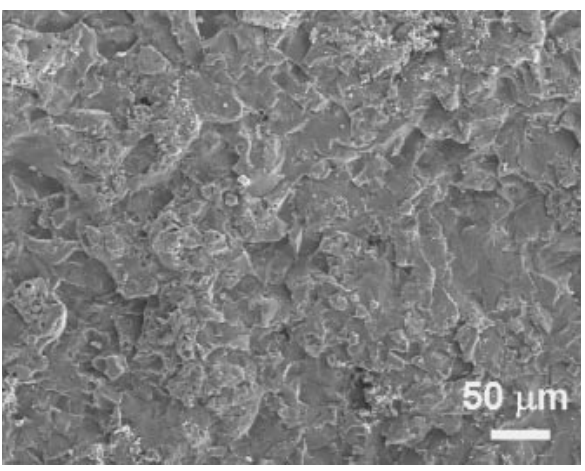

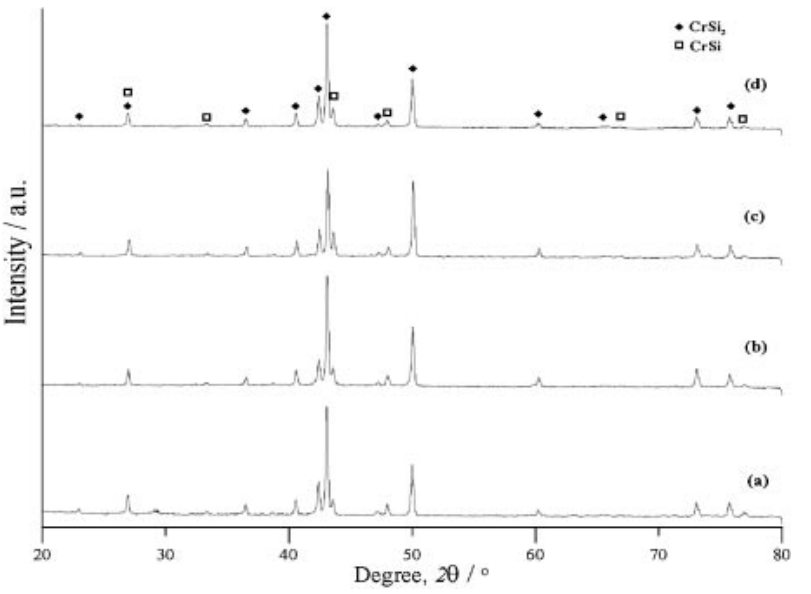

Fig. 5 XRD patterns of as-hp treated and after HIP treatment (175 MPa, $4 \mathrm{~h}$ ) at different temperatures for $\mathrm{Cr} 50-\mathrm{Si} 50$ target (a) as-hp treated, (b) $1323 \mathrm{~K}$, (c) $1373 \mathrm{~K}$, (d) $1423 \mathrm{~K}$.

(b)

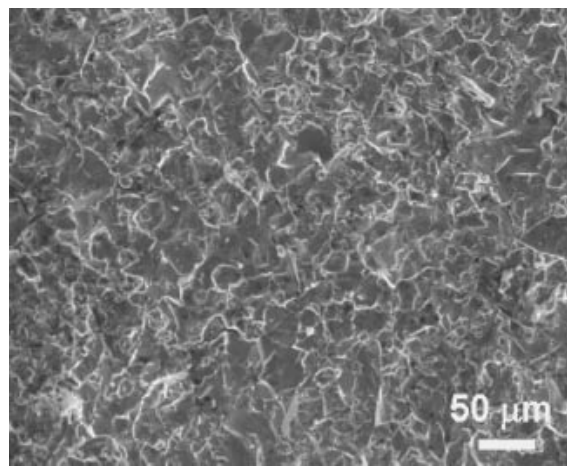

(d)

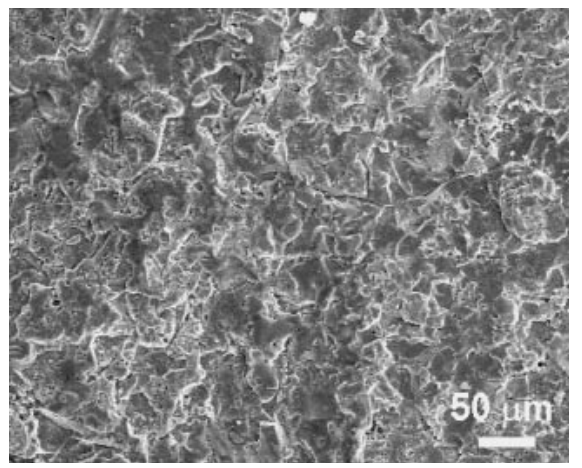

Fig. 6 SEM micrographs of as-hp treated and HIP treatment (175 MPa, $4 \mathrm{~h}$ ) at different temperatures for Cr50-Si50 target (a) as-hp treated, (b) $1323 \mathrm{~K}$, (c) $1373 \mathrm{~K}$, (d) $1423 \mathrm{~K}$.

Nitrogen and oxygen may still store in the pores of the target after HIP. The amount is too little to find out any nitrides or oxides with XRD as long-range order crystals. With the reduced porosity, there were fewer and smaller pores to be adsorbed by nitrogen and oxygen, and the concentrations may go down.

\subsection{XRD analysis}

Figure 5 represents the XRD patterns of as-hp treated and HIP treated at different temperatures $\mathrm{Cr} 50-\mathrm{Si} 50$ target. According to the $\mathrm{Cr}-\mathrm{Si}$ phase diagram, ${ }^{19)}$ the composition of $\mathrm{Cr} 50-\mathrm{Si} 50$ (Cr-50 mass\% $\% \mathrm{Si}$ ) forms two compounds: $\mathrm{CrSi}$ and $\mathrm{CrSi}_{2}$, and the patterns show the same as the phase diagram. The patterns have little change after HIP. It means that the crystal structures have been stable after hot pressing. In this case, HIP after hot pressing improves the target density physically. Both of $\mathrm{CrSi}$ and $\mathrm{CrSi}_{2}$ are stable after they became silicides from $\mathrm{Cr}$ and $\mathrm{Si}$ powder with hot pressing. It shows that HIP would improve the density and porosity, but not change the composition and crystal structure to influence the thin film deposited by the $\mathrm{Cr}-\mathrm{Si}$ target.

\subsection{SEM, TEM observation}

Figure 6 is the secondary electron images (SEI) of as-hp treated and HIP treated at different temperatures $\mathrm{Cr} 50-\mathrm{Si} 50$ targets. It is easily observed that the porosity exists inside the target as hot pressing by Fig. 6(a). Increasing HIP temperature can reduce the porosities of close pores and open pores, 
(a)

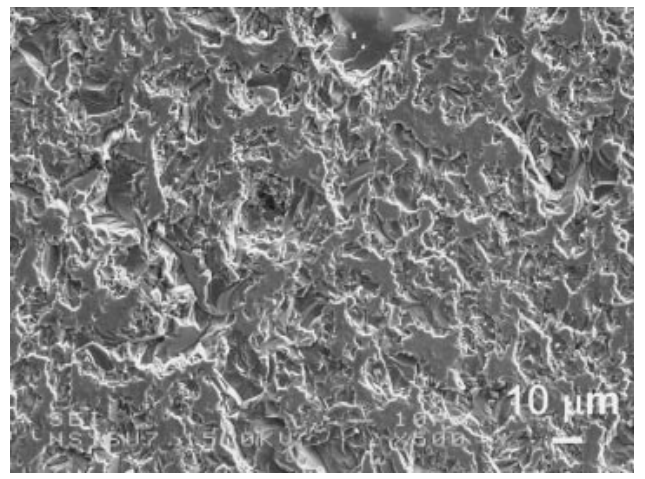

(c)

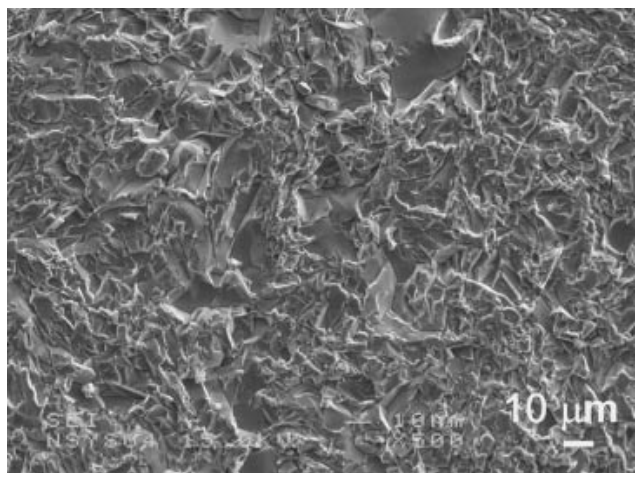

(b)

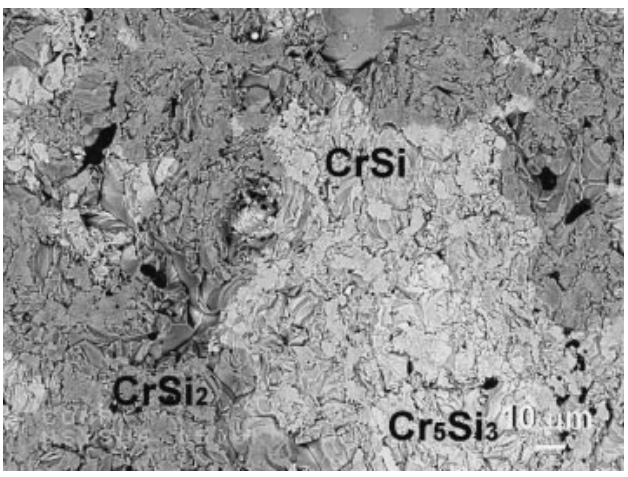

(d)

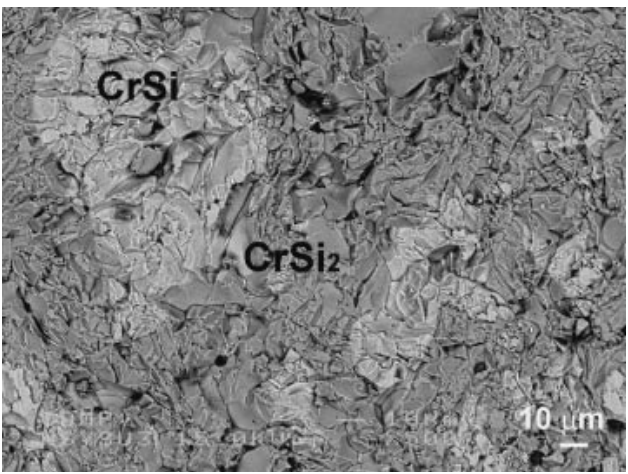

Fig. 7 Comparison of the SEI and BEI micrographs of (a)(b) as-hp treated and (c)(d) $1373 \mathrm{~K}, 175 \mathrm{MPa}, 4 \mathrm{~h} \mathrm{HIP} \mathrm{treatment} \mathrm{for} \mathrm{Cr50-Si50}$ target.

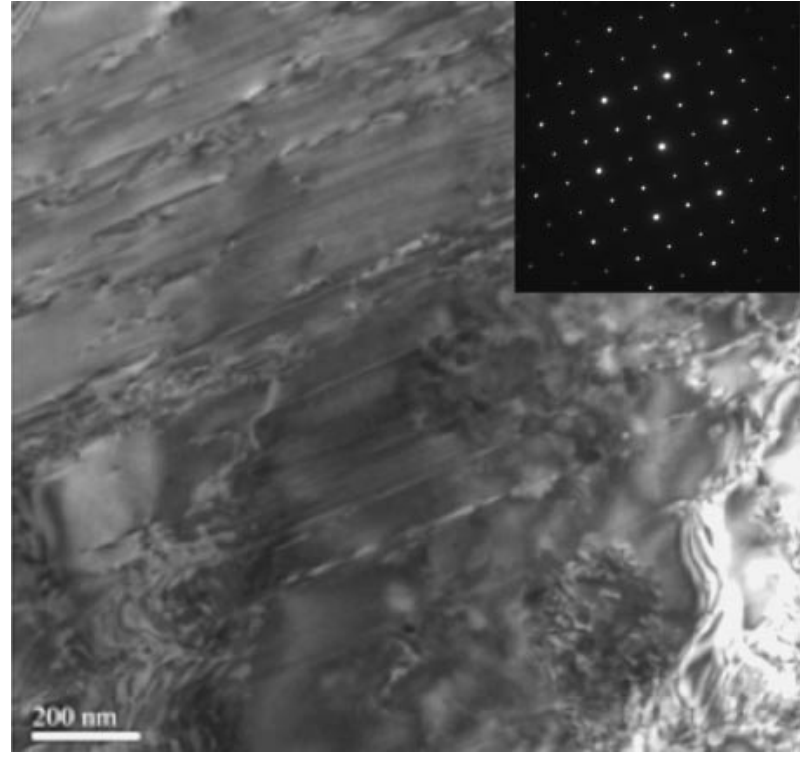

Fig. 8 TEM micrograph and associated electron diffraction of $\mathrm{CrSi}$ [100] for Cr50-Si50 target after $1373 \mathrm{~K}, 175 \mathrm{MPa}, 4 \mathrm{~h}$ HIP treatment.

and the most suitable HIP temperature appeared at $1373 \mathrm{~K}$ as Figure 6(c). HIP treatment clearly eliminated and decreased the porosities. When the HIP temperature increased to $1423 \mathrm{~K}$ as Fig. 6(d), the surface materials would melt partially, and the argon as the HIP atmosphere was involved and trapped. It brought some small pores generating and the porosity increased.

Figure 7 shows the SEI and backscattered electron images (BEI) of as-hp treated and $1373 \mathrm{~K}, 175 \mathrm{MPa}, 4 \mathrm{~h}$ HIP treatment for the Cr50-Si50 target. From the EDS results,

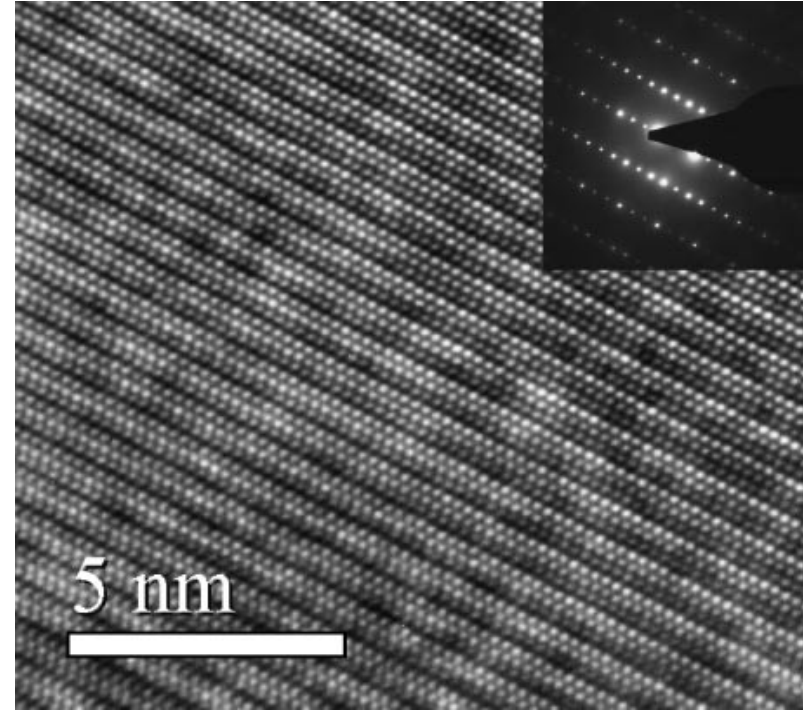

Fig. 9 HRTEM micrograph and associated electron diffraction of $\mathrm{CrSi}_{2}$ [120] for Cr50-Si50 target after $1373 \mathrm{~K}, 175 \mathrm{MPa}, 4 \mathrm{~h}$ HIP treatment.

the BEI images as Figures 7(b) and 7(d) represent that the gray area is $\mathrm{CrSi}$ and charcoal gray area is $\mathrm{CrSi}_{2}$, and the bright zone detected in Fig. 7(b) is $\mathrm{Cr}_{5} \mathrm{Si}_{3}$. It presents that the composition distribution is not so uniform after hot pressing. Because the amount of $\mathrm{Cr}_{5} \mathrm{Si}_{3}$ is too little to be detected by XRD, we can just find it out locally by SEM. In the Fig. 7(d), we can find no $\mathrm{Cr}_{5} \mathrm{Si}_{3}$, only $\mathrm{CrSi}$ and $\mathrm{CrSi}_{2}$ exist in the target after $1373 \mathrm{~K}, 175 \mathrm{MPa}, 4 \mathrm{~h}$ HIP treatment. It shows that HIP can enhance the uniformity of the Cr50-Si50 target.

Figure 8 represents TEM micrographs and diffraction pattern results of CrSi [100] zone of Cr50-Si50 target and Fig. 9 shows HRTEM micrographs and pattern results of 
$\mathrm{CrSi}_{2}$ [120] zone of Cr50-Si50 target after $1373 \mathrm{~K}, 175 \mathrm{MPa}$, $4 \mathrm{~h}$ HIP treatment. From Fig. 8, we can determine the $\mathrm{CrSi}$ crystal structure is cubic from the diffraction pattern. The $\mathrm{CrSi}_{2}$ crystal structure is hexagonal determined from the diffraction pattern of Fig. 9. We can also observe that $\mathrm{CrSi}_{2}$ is lamellar structure existed in the Cr50-Si50 target from Fig. 9. The $\mathrm{CrSi}_{2}$ crystal is near perfect after HIP treatment. This is good for application such as thin film deposition.

\section{Conclusion}

(1) HIP treatment can eliminate the open and close pores of targets. Cr50-Si50 target decreased to $40 \%$ in porosity after $1373 \mathrm{~K}, 175 \mathrm{MPa}, 4$ hours HIP treatment.

(2) Oxygen concentrations of the Cr50-Si50 target would not change so much have after HIP treatment, but Nitrogen concentrations were decreased.

(3) The most suitable HIP parameters of Cr50-Si50 target are $1373 \mathrm{~K}, 175 \mathrm{MPa}, 4 \mathrm{~h}$.

\section{Acknowledgments}

This research supported by the Materials and ElectroOptics Research Division of Chung-Shan Institute of Science and Technology Taiwan. The authors would also like to express their appreciation to ASSAB STEELS TAIWAN CO., LTD.

\section{REFERENCES}

1) W. Arbiter: WADC technical report part I (1953) 53-190.

2) W. Y. Kim and H. Tanaka et al.: Intermetallics 9 (2001) 521-527.

3) Yu. N. Taran-Zhovnir: Mat. Sci. Heat Treat. 40 (1998) 210-216.

4) J. C. Kuang and C. R. Zhang et al.: Mater. Research Bulletin 39 (2004) 923-931.

5) M. Naka and M. Maeda et al.: Vacuum 65 (2002) 503-507.

6) P. Wei and X. R. Wan: Surf. Coat. Technol. 132 (2000) 137-142.

7) S. Haro and R. Colas et al.: Mater. Chem. and Phys. 77 (2002) 831835 .

8) E. Klar: Metals Handbook Ninth Edition Vol. 7 Powder Metallurgy, (American Society for Metals, 1984) pp. 419-443.

9) T. Garvare: Proceedings of the International Conference on HIP-Lulea/ 15-17 June, (The Swedish Institute of Production Engineering Research, 1987) pp. 3-70.

10) M. Koizumi: Hot Isostatic Pressing Theory and Applications, International Conference on Hot Isostatic Pressing, (Elsevier Applied Science, 1992) pp. 11-187.

11) Flow Autoclave System, Inc.: Hot Isostatic Pressing Applications.

12) S. H. Chang and S. C. Lee et al.: IJCMR. 19 (2006) 175-180.

13) S. H. Chang and S. C. Lee et al.: IJCMR. 19 (2006) 181-187.

14) S. H. Chang and S. C. Lee et al.: Mater. Trans. 47 (2006) 426-432.

15) H. Bei and E. P. George et al:: Intermetallics 11 (2003) 283-289.

16) S. C. Lee and S. H. Chang et al.: Mater. Trans. 47 (2006) 2877-2881.

17) W. Czarczynski and B. Dobrazanski et al:: Vacuum 70 (2003) 299302.

18) ASTM C373-88 15.02 (2006).

19) Massalski TB, editor. Binary Alloy Phase Diagrams, 2nd edition, vol. 3 (Materials Park, OH: ASM International, 1990). 